\title{
FEDERICO DE ONÍS Y LA AVENTURA AMERICANA DE LA GULTURA ESPAÑOLA
}

\section{FEDERICO DE ONÍS AND THE AMERICAN ADVENTURE OF SPANISH CULTURE}

\author{
Eduardo Creus Visiers \\ Università degli Studi di Torino \\ eduardo.creus@unito.it
}

Resumen: En este artículo se analiza la interpretación de los vínculos entre la cultura española y la hispanoamericana elaborada por Federico de Onís desde su llegada a los Estados Unidos en 1916 hasta la publicación, en 1955, de España en América. Se examinan las ideas del hispanista sopesándose el rigor, a veces intransigente, con que sostuvo la existencia de una unidad cultural que juzgaba signo de identidad de los pueblos de habla hispana y circunstancia capaz de persistir más allá de toda posible contingencia histórica o limitación territorial.

Palabras clave: Federico de Onís; crítica literaria; literatura hispanoamericana; exilio español; cultura hispánica.

Abstract: This article analyzes Federico de Onís's interpretation of the relations between Spanish and Latin American cultures, from the time of his arrival in the United States in 1916 through to the publication of España en América in 1955. In presenting his ideas, specific attention will be paid to the rigor, sometimes close to intransigence, with which he claimed the existence of a cultural unity that he considered a mark of identity common to all Spanish-speaking peoples, a feature capable of persisting beyond any possible historical contingency or geographical limitation.

Keywords: Federico de Onís; literary criticism; Latin American literature; Spanish exile; Hispanic culture.

Recepción: 21 de noviembre de 2018; aceptación: 6 de marzo de 2019. 
Cuando en 1954 Federico de Onís concluyó, cumplidos los sesenta y ocho años de edad, su labor docente en Columbia University y llegó la hora de los homenajes, discípulos y amigos propusieron la publicación de un volumen que reuniese los textos más representativos de su obra escrita. Aunque Onís declaró el deseo de renunciar a toda ceremonia de despedida, ya que no daba por concluida su actividad universitaria, sí aceptó secundar esta iniciativa y encargarse él mismo de la composición del libro. España en América, impreso en 1955 por la Universidad de Puerto Rico, recoge, junto a los trabajos críticos más difundidos del investigador, otros menos conocidos y hasta alguno inédito: un corpus imponente del que a menudo se ha dicho que no alcanza a ser obra completa, pero en cierto modo la suple. Onís hacía en el prefacio un balance de las dos etapas en que dividía su vida, "la española, de treinta años, y la americana, de treinta y ocho", y refiriéndose a la segunda afirmaba:

En rigor, este cambio geográfico y espiritual no significó ruptura entre las dos, porque la razón que había en el fondo de mi propósito creciente de quedarme en América era el hecho, no ya de que mi trabajo en ella era totalmente español, sino el de que en este continente me sentía más en el centro de España que cuando estaba en España misma. Ya antes de salir de España sentía la atracción de la América española como razón última del ser histórico de España ("Prefacio", en Onís 1955, p. 9).

Un examen somero de la obra crítica de Onís basta para constatar que, en efecto, esta segunda etapa, iniciada en 1916, no supuso ruptura con la labor investigadora precedente, pero sí abrió nuevas perspectivas a sus estudios hispanoamericanos, tempranamente estimulados por la lectura de Menéndez Pelayo y el magisterio de Unamuno. Pocos años antes de redactar esas palabras liminares, en su conferencia "La originalidad de la literatura hispanoamericana", pronunciada en el Colegio Libre de Estudios Superiores de Buenos Aires el 18 de mayo de 1949, Onís había citado admirativamente una reflexión de Karl Vossler a propósito del interés del estudioso alemán por la cultura de América: 
Y decía [Vossler], terminantemente: Si volviera a empezar ahora mi labor literaria, que inicié hace cuarenta años, me dedicaría a estudiar la literatura hispanoamericana, porque es campo totalmente desconocido y tiene un valor en sí mismo tan grande y tan original como cualquier otro. Y además, porque es el campo de mayor interés científico, ya que en América se encuentran vivas muchas manifestaciones históricas que desaparecieron en Europa hace siglos y que ayudarían más que nada a que pudiéramos entender lo europeo. Había un hombre europeo que decía: "Hay que conocer lo americano para entender lo europeo". Lo habían dicho americanos; lo había dicho Sarmiento ochenta años antes ("La originalidad de la literatura hispanoamericana" [1951], en Onís 1955, p. 119).

Aunque Onís parece coincidir con Vossler en su propósito de "conocer lo americano", que mucho tiene de interés por ciertos vestigios de la cultura europea, en realidad a él no le preocupan las manifestaciones que han persistido inalteradas, sin sustancial evolución desde la Conquista, sino aquellas que, habiendo experimentado desarrollo propio, pueden juzgarse testimonio de una tradición viva:

La conservación de costumbres, instituciones, ideas o cosas españolas en América, por abundante que sea -y lo es tanto que la visita a muchos pueblos americanos, o la lectura de los libros, nos dan muy a menudo la impresión de hallarnos ante realidades españolas del pasado más puras e intactas que las que se conservan en ningún sitio de España-, no significa más que tradición muerta, aislamiento, inercia, es decir, lo contrario de la verdadera tradición... La permanencia de España en América tendremos que buscarla, por lo tanto, no como peso muerto o resto arqueológico del pasado, sino como fermento vivo latente en las creaciones nuevas y originales americanas ("La eternidad de España en América” [1942], en Onís 1955, p. 14).

De modo que para Onís la tradición “verdadera” de España subsiste en las formas evolucionadas del mestizaje cultural, que son las originales. Con este criterio afrontará el estudio de las letras hispanoamericanas, aunque es preciso advertir que ni hay equilibrio en su concepto de hibridismo aplicado a esta literatura ni es sustancial el relieve que en ella concede a la influencia de las culturas nativas del continente. A decir verdad, Onís apenas presta atención a lo autóctono americano: registra la admi- 
ración misionera por la bondad del salvaje, de las que nacen la idealización y el tópico, y señala la importancia de figuras capaces de encarnar inéditas síntesis -como el Inca Garcilaso de la Vega, quien "con orgullo español" afirma su condición de indio, o sor Juana Inés de la Cruz, que acierta a aunar en sus versos influencias poéticas inconciliables en la lírica peninsular-, pero observa también que lo hispanoamericano no es en el plano cultural, como no lo es en el biológico, mera hibridación. De hecho, considera que la literatura de la América hispana, producto de circunstancias históricas singularísimas, nace en el momento auroral del descubrimiento:

Creo que la originalidad de la literatura hispanoamericana existe desde el principio, desde el momento en que existe América; no es, como suelen pensar y decir algunos, que estos pueblos desarrollen poco a poco su personalidad, su originalidad, y cada día lleguen a ser más originales... Yo diría sin vacilar, con nuestro gran humanista hispanoamericano Pedro Henríquez Ureña, que la primera obra de la literatura hispanoamericana es el diario que Colón llevaba en su barco cuando viajaba hacia el descubrimiento. Colón escribía ese diario en castellano -porque Colón jamás escribió una palabra en otra lengua que en castellano-y en él están ya todos los temas eternos de la literatura hispanoamericana (“La originalidad...", en Onís 1955, p. 120) ${ }^{1}$.

La realidad de América transforma el espíritu del europeo que la explora, y cuando ese nuevo hombre resuelve expresarse en términos literarios ha de inventar los modos para describir un mundo inédito: de ahí la originalidad "desde el principio" de la literatura hispanoamericana, que hace inapropiado hablar de lentos desarrollos. A esta convicción de Onís pudiera objetarse que las primeras letras europeas en América son, sí, testimonio del impacto de las nuevas geografías, y sobre todo de las nuevas realidades humanas, en la mentalidad medieval de los españoles afincados o en tránsito por el continente, pero tal

${ }^{1}$ En Las corrientes literarias en la América hispánica, libro publicado en inglés por Pedro Henríquez Ureña en 1945 y divulgado en español en la versión de Joaquín Díez Canedo, leemos: "No hace mucho, en una conferencia pronunciada en Buenos Aires (1939), José Ortega y Gasset sostenía que el español -y otro tanto puede decirse del portugués- se convirtió en un hombre nuevo tan pronto como se estableció en el Nuevo Mundo. El cambio no requirió siglos: fue inmediato y el correr del tiempo no hizo sino reafirmarlo" (HenRíQuez UreÑA 2014 [1949], p. 68). 
estupor más parece la natural reacción ante lo insólito del viejo espíritu europeo, al cual no se ve cómo pueda atribuírsele una identidad hispanoamericana desde el primer momento. Se trata de ese espíritu que se muestra reacio a incorporar la realidad de América a una imagen del mundo rígidamente concebida, o por decirlo con las palabras de John H. Elliott, a encajarla dentro de su campo de visión ${ }^{2}$; el mismo que ve América como materialización de una imagen hecha del paraíso terrenal o de la utopía áurea; el mismo que en las crónicas busca en vano las palabras para describir tanta novedad y, ante las dificultades insalvables, ha de resignarse a una prosa doméstica, hecha de convenciones y símiles prestados de los libros de caballerías, y el mismo, en fin, que a América vuelve para -escribirá Pérez de Oliva en 1528- "dar a aquellas tierras extrañas la forma de la nuestra" (apud Elliott 1970, p. 28).

Onís ofrece sus reflexiones acerca de la originalidad de la literatura hispanoamericana cuando los estudios sobre la materia han puesto de manifiesto que el mestizaje surgido en tierras americanas había contribuido a la aparición de una literatura que, pese al fundamento enteramente europeo, incorporaba ciertas tonalidades inéditas, germen de una expresión escrita propia que tardaría aún mucho tiempo en afirmarse, pues la persistente influencia europea en el Nuevo Mundo determinó durante siglos su pensamiento y su expresión escrita dejando poco espacio a elaboraciones novedosas ${ }^{3}$. Las conclusiones de Alfonso Reyes sobre las letras novohispanas evidenciaban que no hubo originalidad -no era precisa- en el teatro misionero del siglo XVI y que luego el criollo no aguantó el embate

2 Elliott (1970, pp. 21-22) afirma: "La realidad de la existencia de América y su gradual aparición como una entidad de derecho propio, más que como una prolongación de Asia constituyó su desafío a todo un conjunto de tradicionales prejuicios, creencias y actitudes. La grandeza de este desafío nos da la explicación de uno de los hechos más sorprendentes de la historia intelectual del siglo xvi: la aparente lentitud de Europa para hacer el adecuado reajuste mental a fin de encajar América dentro de su campo de visión”.

3 Como observa Enrique Anderson Imbert (2014 [1954], pp. 181182): "Europeos trajeron al nuevo mundo su caudal de cultura; y a pesar de que se adaptaron al ambiente, y sus hijos y nietos y tataranietos fueran americanos, esa cultura europea prevaleció... En el siglo XvinI, por ejemplo, cuando ya las colonias parecerían alejadas de las primeras generaciones de españoles, y de las primeras fundaciones de ciudades e instituciones culturales y, por tanto, podría esperarse más originalidad, lo cierto es que una nueva ola europeísta viene a cubrirnos". 
de una dramaturgia peninsular a todas luces superior en términos artísticos. La cultura, viva en las aulas del continente, generó poesía erudita y prosa retórica tan conformes a los moldes de la tradición hispana que es difícil discernir qué relumbres de innovación son ya propios de América. En los más privilegiados sectores de la sociedad colonial proliferó una literatura no de primer orden, cimentada en la reiteración de las formas importadas, cuya mayor virtud fue la de contribuir al creciente refinamiento. Casos como el del Inca Garcilaso de la Vega, capaz de armonizar lo indígena con el más selecto humanismo o el de sor Juana Inés, cuya poesía cierra con brillantez un largo ciclo literario, son notabilísimos por lo excepcionales. El barroco en América no presenta ejemplos de originalidad comparable. En el ámbito de las letras, la novedad ha de buscarse en el Modernismo que Rubén Darío lidera, en obras fundacionales como el Facundo o el Martín Fierro, en novelas como La vorágine, Don Segundo Sombra o Doña Bárbara, y desde luego en escritores del calibre de Jorge Luis Borges, Alfonso Reyes, Pablo Neruda y tantos otros cuyas obras han determinado la evolución de nuestras letras.

Onís celebra con toda razón el carácter innovador de escritores hispanoamericanos como Darío, Sarmiento, Hernández o "el gran Güiraldes", los cuales se cuentan entre sus preferencias, sin dejar de consignar que "estas culturas de América son culturas europeas trasplantadas a América" y que, en consecuencia, nos encontramos a uno y otro lado del Atlántico "con el mismo contenido de cultura" ("La originalidad...", en Onís 1955, pp. 119-127). En ello, sostiene, no hay menoscabo de la originalidad literaria hispanoamericana, porque se trata de los mismos contenidos que han compartido las principales literaturas de Europa sin ver comprometida su singularidad. Estos argumentos nos dejan la impresión de que la presencia imponente de la cultura occidental en las letras de América ha relegado a lugar marginal toda influencia nativa, por más que en alguna ocasión Onís sostenga que manifestaciones como la corriente indigenista o el negrismo no deben interpretarse como "pintoresquismo romántico o regionalismo costumbrista", sino como lo que de veras son: "sustancia y expresión del propio ser de América" ". Pero si es así, ¿por qué estos aspec-

${ }^{4}$ Estas palabras provienen de su artículo "Valoración", publicado por la Revista Hispánica Moderna (ONís 1952, p. 150) y no recogido en España y 
tos quedan enteramente soslayados -que no inadvertidos- en su reflexión sobre obras tan representativas como la martiana, por ejemplo? Y aun su interés por un poeta como el antillano Luis Palés Matos pudiera parecer, a este respecto, un querer ver las cosas con distancia. Tal actitud de Onís lo sitúa en los antípodas de interpretaciones como la de su admirado Martí, para quien "ni el libro europeo ni el libro yanqui daban la clave del enigma hispanoamericano", y a la misma insalvable distancia de la idealización de Rodó, o del mesianismo de Vasconcelos, o de la visión exaltadora del mestizaje que, afrontando el prejuicio racial, atraviesa de uno a otro extremo la entera América Latina y hace suya un escritor como Carpentier, o de la críptica conceptualización del barroco americano como estética de transculturación y "contrarreconquista" propuesta por Lezama Lima, por citar sólo algunos ejemplos notorios en el plano literario.

Bien es verdad que enunciados como el de Martí habían podido fomentar convicciones que, despejadas de su candor patriótico, poca sustancia conservan, porque lo que vale enteramente para las culturas amerindias, y de modo parcial para la densa realidad interracial del continente, no es aplicable al elemento humano que el encuentro de lo hispano y lo americano genera en los nuevos espacios; encuentro sobre el que el libro europeo tiene bastante que decir. Pero es también cierto que las ideas de Onís, que no discurren por los fértiles terrenos de la indagación sobre la propia identidad ni por los fácilmente inflamables de los nacionalismos americanos, podían ser adscritas a cierta inflación de hispanidad percibida en el siglo xx como dañosa injerencia, o como "exceso de celo" en la amable y algo irónica expresión de Carpentier (1990, p. 364), entre quienes eran dueños de culturas y lenguas diversas, habían experimentado el difuso avivarse de la propia conciencia nacional y podían encarnar un ideal de mestizaje que lo era de adición y riqueza. Al filo del medio siglo, la posición de Onís al respecto es, cuando menos, ambigua, porque si de un lado defiende con argumentos que dejan pocas dudas la hispanidad constitutiva -y por muchos conceptos excluyente- de América, se muestra,

América. La misma idea aparece en "Martí y el Modernismo" ([1953] ONís 1955 , p. 631).

5 La afirmación procede del célebre escrito de José Martí, "Nuestra América", publicado en La Revista Ilustrada de Nueva York el 1 de enero de 1891 (se cita aquí por MarTí 2004, p. 164). 
de otro, conocedor de los riesgos de una cerrada percepción eurocéntrica de lo americano:

El concepto de Europa y de toda esta historia universal -con la división en las edades antigua, media y moderna- es algo que se inició ya muy avanzado el siglo XVII; siguió gestándose y es, en rigor, un producto de la ideología del siglo xviII. Al crearse esta idea de esa Europa, de esa civilización occidental, en el siglo XVIII, América se miró y se explicó como una expansión de Europa. Los europeos crearon una historia egocéntrica ("La originalidad...", en Onís 1955, p. 118).

De modo que América no puede ser concebida como expansión de Europa; a ese erróneo hábito historiográfico opone Onís la visión de europeos con experiencia americana, como Humboldt, e iniciativas tales como la que ejemplifica la Historia antigua de México (1780) del jesuita expulso Francisco Javier Clavijero, modelo de una aproximación no por parcial menos comprensiva:

El padre Clavijero, un mexicano, escribió su magnífica historia de México, y en aquella historia defendía el valor, la cultura, la superioridad manifestada en muchas cosas, de sus paisanos; y lo escribió el padre Clavijero, jesuita, hijo de padres españoles. Lo que él defendía era el México total: las civilizaciones antiguas, indias y el México moderno ( $i d$.$) .$

"México total" que invita de modo tácito a pensar en una "América total", sin exclusiones, como objeto de verdadero conocimiento histórico. En cualquier caso, no es esa visión omnicomprensiva lo que Onís ha perseguido en su investigación, circunscrita al estudio de una realidad cultural hispanoamericana en que lo autóctono del continente es sólo uno de sus elementos constitutivos: el percibido como más endeble. Onís concibe la cultura española como clave de la hispanoamericana, la cual representa su prolongación en más vastas geografías y en realidades sociales nuevas. Y dado que el hombre hispanoamericano se genera en la transformación del europeo ante la realidad inmensa de las tierras descubiertas, sus temas serán los derivados del estupor ante un mundo improvisamente acrecido y sus actitudes vendrán dadas por el ansia de novedad, desarraigo y libertad que lo han impulsado al viaje y la aventura. Desde las más tempranas manifestaciones literarias colonia- 
les, observa Onís, estos valores comparecen como esenciales y no como reacción contra el propio pasado; son sentimientos gestados en la España de la Reconquista que el Nuevo Mundo vigoriza; son la herencia viva de Hispanoamérica, y siempre que el hombre americano busque originalidad y alcance a crear una obra de valor universal, el resultado tendrá "carácter netamente español al mismo tiempo" ("La eternidad...", en Onís 1955, p. 18). Esto se observa principalmente en la literatura, pues es en las obras americanas que han sabido apartarse de la tradición española, o combatirla incluso, para afirmar su propio carácter -y Onís suele pensar en Sarmiento, en Hernández, en Martí, Rodó o Darío-donde acaba por manifestarse "más vivo y patente el espíritu español" $(i d .)^{6}$. Y es herencia perdurable, porque la organización política y las estructuras impuestas por España habrán podido ser desmanteladas y sustituidas por otras, pero aquello que tiene valor de unidad y universalidad se revela inamovible sustrato de la América hispana.

A la luz de estas consideraciones, tanto la originalidad "desde el principio" que Onís postula como el concepto de integración de ambas culturas, americana y europea, señalado por la crítica como presupuesto de su obra, deben ser cuidadosamente matizados. Al final de un largo ciclo vital y a la hora de los balances, Onís insistirá en sostener tal originalidad primigenia, pero parece igualmente persuadido de una duradera coexistencia sin equilibrio de lo trasplantado y lo autóctono (no entendido esto último como pervivencia cultural precolombi-

${ }^{6}$ Es idea temprana en Onís (aparece en su discurso de 1920, "El español en los Estados Unidos", para la apertura del curso de la Universidad de Salamanca) y de proveniencia unamuniana. En un artículo publicado en 1907 en La Nación de Buenos Aires, que lleva por título "Taine, caricaturista", escribe don Miguel: "pocas veces se me aparecen los americanos más radical y profundamente españoles, o si se quiere ibéricos, que cuando, como en el caso del gran Sarmiento, gustan de renegar de España. ¿No renegamos acaso de ella siete veces al día los españoles estrictos?”. Y en 1909, en su artículo "De cepa criolla", afirma, no menos categórico, "que quien quiera encontrar en la literatura criolla algo profundo y netamente español, debe ir a buscarlo, como yo lo he hecho, en Hidalgo mismo, en Ascasubi, en Estanislao del Campo, en José Hernández. Todo ello es profunda e intensamente español, incluso en lenguaje. Como dije en un estudio, que hace ya años dediqué al Martín Fierro, parece que al encontrarse los españoles ahí en condiciones sociales y de lucha análogas a las que aquí produjeron nuestros viejos romances, el alma del Romancero resucitó" (UnAmuno 1968, pp. 594 y 532, respectivamente). 
na, sino como producto de moderna evolución independiente), en lo esencial no muy diversa de la que ya en un texto de 1924 definiera en modo bien explícito:

La literatura de América -y ahora nos referimos tanto al sur como al norte- es, como toda su civilización, una expansión de Europa; pero la civilización europea, al transplantarse a otro suelo, al vivir en nuevas condiciones geográficas, económicas y sociales, ha ido adquiriendo gradualmente un sello propio y ha llegado a ser una forma nueva y peculiar de aquella civilización. Muchos de los productos literarios hispanoamericanos corresponden completamente a los movimientos creados en Europa, y aunque a menudo sean productos de primer orden, dignos de compararse con los mejores europeos, en rigor no enriquecen la literatura universal con nada fundamentalmente nuevo. Pero hay otros productos, quizá más defectuosos, más vacilantes, más rudos y primitivos, más vagos y confusos, que nos suenan a algo nuevo, vibrante, original, que inútilmente buscaríamos en las literaturas europeas, y que no es otra cosa que el alma americana que empieza a alentar aquí y allá buscando expresión en las formas más diversas. Estas obras, muy a menudo despreciadas e incomprendidas, son sin duda las más valiosas de la literatura hispanoamericana y las que vivirán en el porvenir ("El cuento en América” [1924], en Onís 1955, p. 579).

Si todo el cimiento de la cultura hispanoamericana ha de buscarse en la española, si aquélla existe por decantación de ésta, el margen para cristalizaciones y originalidades futuras $-\mathrm{y}$ ya bien presentes en el caso de la literatura rioplatense- queda tan afirmado como circunscrito a los azares de una lenta e imprecisada evolución ${ }^{7}$. Se trata, para Onís, de un fenómeno digno del

7 "El gaucho ha sido durante un siglo un factor esencial de la historia argentina y uruguaya y el fermento de una literatura que tiene todos los caracteres de una literatura nacional" ("El cuento en América", p. 582). En "El Martín Fierro y la poesía tradicional", también de 1924, recoge Onís, puntualizándolo, el juicio de Leopoldo Lugones y Ricardo Rojas según el cual pertenece el Martín Fierro a la epopeya nacional de la República Argentina. Onís considera que el resto está por verse o por hacerse. En "La originalidad..." afirma: "Ya empiezan a definirse para todo el mundo los valores que América ha tenido en los últimos cien años. Y cuando pasen otros cien, América, que no habrá perdido su originalidad, adquirirá más clara conciencia de su propio valor y presentará al mundo otras figuras que ya se van definiendo, y otras que todavía no hemos alcanzado a valorar" (ONís 1955, p. 127). 
mayor interés, porque esos rudos brotes de originalidad americana anuncian, desbrozada la mera imitación, los frutos del injerto espiritual hispánico, y son, por ello mismo, materia idónea para el examen de la propia cultura. De hecho, la investigación de Onís en sus primeros años en tierra americana es, en buena medida, su personal aporte a la interpretación de la cultura española: labor de elucidación a que habían contribuido figuras cimeras como Costa o Maeztu en el terreno ideológico y político; Ganivet y Unamuno en el histórico y filosófico; Azorín, Machado o Baroja en el literario; Zuloaga en el pictórico... ${ }^{8}$ Quedaba por abordar el más vistoso de sus avatares: la aventura americana de la cultura española, y sería Unamuno quien orientara a un muy joven Onís en esa dirección. "El contacto diario con Unamuno -recuerda Onís- me hizo vivir durante mi juventud en un ambiente de americanismo, que ha sido la fuerza principal que me ha guiado en la labor de toda mi vida consagrada a América" ("Bolívar y Unamuno" [1945], en Onís 1955, p. 589). Lo que Unamuno había intuido, a veces de manera muy certera, por medio de un conocimiento distante y libresco, Onís podría constatarlo en el directo contacto con la realidad americana. $\mathrm{Y}$ es preciso agregar que el influjo unamuniano no fue de un cerrado hispanocentrismo, como bien lo prueban tanto la condena que hace el gran escritor de toda

8 En "El humorismo de Julio Camba", texto publicado en 1927 en la revista Hispania, luego reproducido como prólogo de La rana viajera en edición de Health e incluido en España en América, alude Onís a estos precedentes tras observar que "es evidente que desde el siglo XviII hasta ahora la conciencia de la diferencia entre España y el resto de Europa en conjunto es la idea que ha informado todo el pensamiento y la acción españoles, y los del mundo respecto de España. En los últimos treinta años es cuando este sentimiento ha adquirido máxima agudeza e intensidad, hasta convertirse en la preocupación más dominante y característica de la época contemporánea" (ONís 1955, p. 545). Y en su discurso de 1929, "Ritmo y cultura. El baile de la Argentina", también recogido en España en América (pp. 95-100), Onís afirma ser "un hombre que tiene a España como tema principal de estudio y de preocupación". Antes de Unamuno, América había sido objeto del interés de Juan Valera y Marcelino Menéndez Pelayo. A este respecto, observaba Gonzalo Torrente Ballester (1984, p. 589): "La generación del 98 no descubrió el tema americano. Los que le tratan lo reciben en herencia de la generación anterior. A Menéndez Pelayo y a Valera caben todos los honores del descubrimiento, parcialísimo, limitado, pero efectivo. Las Cartas americanas, por ejemplo, ofrecieron a la indiferencia peninsular el hecho de una literatura trasatlántica, con características propias algunas veces, en trance de autoctonía”. 
tentativa española por ejercer el monopolio de la cultura hispánica, cuanto su censura de un espíritu de imitación que en el plano cultural había supuesto en América largas y estériles dependencias de los modelos europeos. Tal estima de una originalidad sin vasallajes subsistirá en Onís, aun cuando la discrepancia con el maestro se manifieste, y muy tempranamente, en otros importantes aspectos ${ }^{9}$.

En América, Onís dirá sentirse más en el centro de España que cuando estaba en España misma, lo que significa que nada le impide sentirse allí en el meridiano de un debate que a lo largo del siglo xx se afana en actualizar lo menos trasnochado de las inquietudes noventayochistas sobre el problema patrio. De tal conciencia de centralidad arranca su obra crítica de madurez, pues la distancia geográfica no es en su caso obstáculo sino acicate. El distanciamiento parece haberle ofrecido, además, una esencial intuición de lo que el hombre americano es:

Éste es el hecho inicial en todo americano, la voluntad de dejar a Europa, que se ha repetido hasta hoy en el alma de cada uno de los millones de europeos que han llegado a las costas de América. No hay diferencia esencial entre la actitud inicial y el proceso posterior de americanización de los primeros descubridores, conquistadores y pobladores españoles y la del último inmigrante. Se ha notado siempre el hecho de que muchos de estos inmigrantes tuvieron como motivo de su salida de Europa y venida a América una disidencia de carácter religioso, político o económico. El hecho de la disidencia, base inicial de todo lo americano, lo encontraríamos igualmente en todos los que a América han venido, y será más patente en aquellos casos, como cuando se trata de los españoles en el siglo XVI, en los que no había otro motivo o causa determinante más que el puro deseo de marcharse. Por debajo de toda intención confesa o visible, como la busca de la riqueza, la propagación de la fe o la extensión del imperio, había en ellos la más honda de trasladarse a nuevas tierras, romper los lazos con la tierra abandonada y buscar nuevas posibilida-

9 "Al pasar a la universidad -dice Onís en su discurso de 1912 en la Universidad de Oviedo- me encontré en seguida con una personalidad tan sugestiva, tan intensa, tan variadamente culta y tan enérgicamente original como la de don Miguel de Unamuno... Los años que han pasado desde entonces hasta ahora me han hecho llegar a pensar de manera opuesta diametralmente a la suya, y a estimar de muy diferente modo el valor de sus ideas" ("El problema histórico de la universidad española" [1912], en ONís 1955, p. 60). Sobre sus discrepancias con Unamuno, véase C. DE ONís 1985. 
des para la actividad individual ("La eternidad...", en Onís 1955, pp. 15-16).

Salvo que esa "voluntad de dejar a Europa", esa tendencial disidencia y el "puro deseo de marcharse" en busca de mejor horizonte son rasgos definitorios del propio Onís. Desde la identificación con los anhelos atribuidos al español transterrado se observa y se define la presunta esencia de la América hispana. A este elemento subjetivo se suma otro no menos determinante, porque la perspectiva americana propicia, como reconocerá el propio Onís en un breve artículo de 1927, una "visión idealizada y translúcida de la patria lejana" capaz de depurar contornos ${ }^{10}$. Se explica así que Onís sostenga, contra el hecho probado, que las principales motivaciones de los colonizadores fueron menos materialistas que existenciales, y proceda a una dignificación sistemática de la historia que le mueve a asumir la interpretación de la Reconquista desde la atribución al individuo español de impulsos tan perfectamente universales como el ansia de libertad y el espíritu de conquista, o a presentar la Inquisición española no en su vertiente represiva, sino como instrumento de unidad nacional y hasta como "garantía de libertad" en el bien cercado redil de la ortodoxia. Esto último se afirma en el estudio introductorio a su edición de la obra de fray Luis De los nombres de Cristo:

Porque sería radicalmente distinto el sentido de dicha valoración, según que pensemos el Santo Oficio como un poder externo, que ejercía un influjo opresor sobre un ambiente hostil, o simplemente como un órgano que recogía y regularizaba aspiraciones y actividades que surgían espontáneas del ambiente. Y no sólo se deduce de nuestro proceso que era este último el caso, sino que se deduce más: que la Inquisición venía a ser muy a menudo

10 "Nuestra visión idealizada y translúcida de la patria lejana no es una falsificación ni un sueño; es, por el contrario, una visión depurada en la que las líneas de su contorno adquieren una significación y beatitud que nunca pudimos apreciar cuando estábamos dentro de ella" "Nuestra España" [1927], en Onís 1955, p. 101). Ya en 1920, en su discurso en la Fiesta de la Raza celebrada en New York, decía Onís: "Yo creo que la España vencida y humillada por pueblos nuevos y pujantes, lleva en el fondo de su historia y de su cultura una concepción de la vida y del hombre más profunda, más humana, más verdadera, más llena de promesas para el porvenir que la que hasta ahora ha dominado en el mundo" ("Unidad y variedad hispánicas" [1932], en Onís 1955, pp. 22-23). 
quien liberaba a los pensadores de las coacciones del ambiente, convirtiéndose en una garantía de libertad, al menos dentro de la ortodoxia ("Luis de León” [1914], en Onís 1955, p. 302)¹1.

Y es que en materia religiosa elude Onís registrar el clima de conflictividad de la España medieval y renacentista, limitándose a elogiar cierta presunta "actitud conciliadora" que habría prevalecido hasta el mismo umbral de la Contrarreforma, en que como a regañadientes se abandona para inaugurarse la más persistente de las divergencias con toda forma de modernidad europea. Son muchos los frentes que deja abiertos argumentación semejante, que servirá luego de cierre a un trabajo tan representativo como "El concepto del Renacimiento aplicado a la literatura española" ${ }^{12}$, pero aquí interesa observar que a esa modernidad Onís no vacila en oponerle los valores de una hispanidad transfigurada. Así, es a la "originalidad" de la historia de España a la que se adeuda el desconocimiento por parte de los historiadores de lo que en ella sucede entre fines del siglo XV y principios del XVI; desconocimiento que explica tanto lo dispar de las interpretaciones sobre el Renacimiento español como el generalizado menosprecio ${ }^{13}$. Es a un pueblo hispánico "más dado a la acción que a ninguna otra cosa" al que

11 Los tres volúmenes de su edición se publicaron en Madrid (Ediciones de "La Lectura") entre 1914 y 1922.

12 Onís publicó este texto en sus Ensayos sobre el sentido de la cultura española, impreso en Madrid por la Residencia de Estudiantes en 1932, y lo recogió después en las pp. 285-295 de España en América. El texto es representativo por constituir la revisión de una interpretación precedente -expuesta en su discurso de 1912 para la apertura del curso de la Universidad de Oviedo-y un testimonio del perdurable interés de Onís por este período literario, cuyo estudio había estado entre sus principales proyectos intelectuales. Ya en enero de 1912 confiaba a Unamuno su intención de dedicarse "de lleno a estudiar con riguroso método histórico el renacimiento español" (apud García Morales 1998, pp. 489-490).

${ }^{13}$ Menosprecio que Onís hace extensivo a la entera cultura hispánica, objeto de las más encontradas reacciones: "El hecho de que los amigos e intérpretes de la cultura española en el extranjero sean pocos pero sean al mismo tiempo figuras extraordinarias y originales, de las que piensan por sí mismas y son capaces de levantarse sobre los lugares comunes del ambiente, demuestra que lo español es difícil por ser distinto, por ser creación original y única, ante la que no cabe otra posición sino la de entenderla o no entenderla, la de enriquecerse a su contacto o la de estar ciego ante ella, la del amor o la del odio" ("Waldo Frank y la cultura española" [1930], en ONís 1955, p. 91). 
se atribuye la distancia de "las realidades y las posibilidades del Renacimiento italiano", al parecer menos activo. Es a un doble ideal de unidad nacional y unidad moral de Occidente al que se supedita el enorme esfuerzo de "conciliación de la tradición y el progreso" que en la España del cardenal Cisneros se opera por medio de instrumentos como "la Inquisición y la intolerancia religiosa, que tenían sin duda a sus ojos y a los de su tiempo una justificación y un sentido mucho más humano de lo que solemos pensar" ("El concepto de Renacimiento aplicado a la literatura española" [1926], en Onís 1955, p. 294). Y en una reseña del libro de Aubrey F.G. Bell, Luis de León. A study of the Spanish Renaissance, Onís observa:

El señor Bell va más allá y afirma que no sólo España cuenta en la historia de la cultura moderna por sus contribuciones a las corrientes que solemos considerar como típicamente modernas por haber sido las dominantes en el resto de Europa, sino que su obra peculiar y propia en contra de estas corrientes no necesita ser disculpada o atenuada, sino que puede y debe ser justificada como producto de un ideal de civilización en muchos aspectos más prudente, más amplio y más humano que el que triunfó en el mundo moderno. Esta posición -que está muy de acuerdo con el nuevo espíritu europeo creado por la guerra- es mucho más fuerte que la de los apologistas del siglo XIX: a España no se la puede reivindicar por medio de atenuaciones o concesiones parciales conducentes a encajarla dentro de los valores europeos modernos; es preciso, como hace el señor Bell, aceptarla en su totalidad, lo cual no es posible ciertamente sin una rectificación o superación de los valores modernos ("Luis de León y el Renacimiento" [1926], en Onís 1955, pp. 315-316) ${ }^{14}$.

Entendido este ideal "más amplio y más humano" como el producto de una hispánica resistencia -aunque en realidad se tratase de una dificultad de orden financiero- a adoptar los valores del capitalismo emergente en los países del norte europeo, el lector de Onís mejor dispuesto no habría tenido dificultad en secundar una tesis que contribuía, además, a explicar las diferencias irradiadas desde Europa al entero dominio americano. El escritor venezolano Mariano Picón-Salas (1953, p. 803) observaba en este sentido que

${ }^{14}$ El libro de Bell se había publicado en Oxford (Clarendon Press) en 1925 . 
hay en nuestros orígenes, y contra la otra corriente pragmática y utilitaria que ya comenzaba a formarse en el norte de Europa y que llegaría a su apogeo en el industrialismo y la civilización maquinista del siglo xx, cierto desdén e inferioridad económica que nos retrasaría en la gran aventura técnica y utilitaria del mundo moderno.

Pero tampoco está de más recordar, como el citado autor lo hizo en alguna ocasión, que nada parecido al vivaz debate sobre la Conquista que pudo desarrollarse en la América hispana existió en la del Norte, drásticamente colonizada, casi un siglo después, con los más utilitarios criterios. La controvertida tesis de la superioridad de las naciones protestantes, adalides de una libertad y un progreso dignos de ser adoptados de grado o por fuerza por la entera humanidad, que de François Guizot a nuestros días viene gozando de vitalidad excelente, fue en el siglo xx objeto de oportuna discusión histórica. Onís parece hacerse eco de ese debate al advertir en la modernidad europea que arranca de la Reforma un ideal menos "prudente" y "humano" de lo que solía afirmarse. Pero es argumento que formula con cautela: reclamar en nombre del pensamiento renacentista español que coexistió con la intolerancia religiosa, y con las nada admirables formas del colonialismo hispánico, una "rectificación de los valores modernos" era, qué duda cabe, arduo empeño.

Las delicadas cuestiones históricas en que el esfuerzo apologético de Onís se revela más enérgico conciernen de modo más o menos directo a la realidad de América, donde seguían siendo factores de seguro impacto emotivo el instinto depredador del conquistador -bien que se hubiera reconocido que no era éste un rasgo privativo español- o la constricción moral y religiosa ejercida por la Iglesia -aunque también en este punto se admitiera que la Inquisición había sido más laxa en América que en España, al quedar limitado en las colonias el poder eclesiástico. En cuanto a la acusación de resistencia retrógrada a una modernidad europea que mediado el siglo XviI había ido imponiéndose en todas partes, a nadie se le ocultaba que España había fomentado de puertas adentro la reacción más deplorablemente eficaz, pero no era menos obvio que su política exterior, incapaz pese a la violencia ejercida de reprimir tanto la proliferación de revueltas indígenas como los fermentos de moderno pensamiento revolucionario, tenía como contrapar- 
tida el influjo de una ideología progresista que la Ilustración española adoptó a partir de los más avanzados criterios europeos y acertó a transmitir a América. Como señalaba también, en un valioso libro, Mariano Picón-Salas (1944, p. 216),

sólo por miopía histórica o estrecho nacionalismo cantonal (y los estudios históricos en nuestros países han adolecido de ello) pudiera negarse la estrecha correlación que este pensamiento económico y educativo de las colonias tiene con el de la España de los mismos días... la influencia ya perceptible de las ideas cosmopolitas -inglesas o francesas- en el pensamiento criollo de entonces, se ejercita sobre un fondo común de ideología espanola ${ }^{15}$.

No deja de ser llamativo que Onís renuncie a estos argumentos que la tradición liberal española le brinda, y en su defensa de la singularidad histórica patria prefiera al elogio de actitudes que contribuyeron a aguijar los anhelos de independencia en las colonias, la justificación de una continuidad antimoderna muy propia del conservadurismo español, vivero de toda suerte de inercias reaccionarias.

Se trata, pues, de cuestiones de gran alcance en Hispanoamérica, no sólo porque atizaran en su día el fuego del discurso revolucionario, sino también por subsistir en las formas más críticas de la interpretación de la historia del continente. La atenuación de su impacto podía representar para Onís el modo de afrontar las razones de una voluntad de ruptura ya resuelta en el orden político en perjuicio de España, pero latente aún como amenaza en el plano de la cultura. Nada objeta Onís a la independencia política, y elogia sin reservas la autonomía

15 En cambio, Onís se refiere a la influencia francesa como fenómeno paralelo en Hispanoamérica y en España, y lo hace con el fin de demostrar que ese influjo no pudo en ningún caso ser motivo de distanciamiento: "Los americanos no se alejaron de España al afrancesarse puesto que España se afrancesó igualmente. El siglo XVIII había sido ya un siglo de afrancesamiento. Los americanos hicieron su revolución en la que jugó su parte la ideología de la revolución francesa, y los españoles hicieron la suya igualmente, y los principios y las leyes y las instituciones de la Francia democrática se han incorporado durante el siglo Xıx a la vida pública española" ("Francia y la cultura española" [1918], en ONís 1955, pp. 33-34). La misma idea comparece en las páginas introductorias de su célebre Antología de la poesía española e hispanoamericana (1882-1932), publicada por el Centro de Estudios Históricos en 1934. 
intelectual de América; sus reparos conciernen a la negación o al olvido de una unidad cultural que ha mantenido siempre puentes tendidos entre España y el continente. Es en ese contexto en el que ha de situarse su reivindicación de lo americano como potencial incremento de las mejores esencias hispánicas, las de una herencia cultural injustamente maltratada. Esta tendencia idealizadora de Onís, aproada menos al rancio patrioterismo que a acrecer la sugestión de su visión integradora de la cultura hispánica -y a la que no fueron ajenas ni la orientación unamuniana en años de influencias ni el magisterio de Pidal ni su propia intervención en los proyectos divulgativos de la Residencia de Estudiantes o del Centro de Estudios Históricos de Madrid-, se manifestó en la forma de un "españolismo radical" a partir de su experiencia americana ${ }^{16}$. Y pudo muy bien agudizarse durante la Guerra Civil y, en mayor medida aún, tras la contienda, hallándose el propio Onís en situación de exilio voluntario. El drama de la guerra en España lo sintió hondamente, a pesar de la distancia física:

Yo, aunque no he sufrido daños materiales directos -confiaba el 13 de abril de 1937 a su amigo Américo Castro-, los estoy sufriendo muy grandes materiales y morales a través de mi familia más inmediata y de mis mejores amigos. Y estoy aplastado moralmente por el triste destino de nuestra patria, que siempre preví (cf. Albert Robatto 2003, p. 137).

Preocupación que se traduciría en eficaz socorro a los exiliados republicanos: en carta a Gabriela Mistral del 19 de febrero del mismo año informaba a la amiga de sus gestiones en ese sentido y le proponía coordinar la ayuda a los afectados por una emigración que, pese a las lamentables circunstancias, habría de tener su aspecto positivo, pues, observaba, "puede servir para que los españoles empiecen a conocer a América, y salgan de un aislamiento que tanto daño nos ha hecho a todos" (apud Arrigoitia 1985, p. 44). La Guerra Civil fue motivo de discusión en las ter-

${ }^{16}$ La cual fue para él, al menos en sus primeros años norteamericanos, un vivir en "polémica constante e inevitable entre el ambiente y la propia personalidad", según afirmaba en su discurso de apertura del curso en la Universidad de Salamanca, pronunciado el primero de octubre de 1920 ("El estudio del español en los Estados Unidos" [1932], en ONís 1955, pp. 679702), en que alude también a la crítica a que se ven sometidos los propios sentimientos, las convicciones y los hábitos en el "ambiente implacable y hostil" del país extranjero. 
tulias de Onís, y hubo de serlo para él de malestar íntimo por una actitud de neutralidad que no dejó de reprochársele ${ }^{17}$. En otra carta a Gabriela Mistral, fechada el 21 de febrero de 1939, Onís coincidía con la escritora en que "todo lo de España es trágico", y su amarga reflexión sobre las circunstancias históricas le llevaba a concluir que, a la vista de la catástrofe, a él no le quedaba otro remedio que seguir luchando por la continuidad de la cultura española en América (cf. Arrigoitia 1985, p. 45, y Albert Robatto 2003, p. 225). Onís sentía que era aquélla su misión como intelectual español, y en años sucesivos sus esfuerzos profesionales se encaminaron a ese objetivo.

Ello nos permite entender mejor su obsesiva reivindicación de la impronta hispánica en toda forma de originalidad americana, que se matiza y perfila en algunos trabajos de los años cuarenta, y explica asimismo su censura de conceptos como el de poesía afroantillana-sin alusión a lo hispánico-, justificada en razones no muy diversas de las que propiciaron su rechazo del término latinoamericano como sustituto de hispanoamericano o su desencuentro con Mistral a propósito del indigenismo. Pero una cosa era volver la vista atrás y reivindicar la raigambre hispánica de la cultura americana, lo cual había hecho Onís desde su mismo arribo al continente, y otra muy distinta dirigir la mirada hacia el incierto porvenir. Onís hubo de sentir al estallar la Guerra Civil -o incluso antes, si era cierto que, como escribía a Castro en el año 37, "siempre previó" el trágico destino de su país- que ante la amenaza de disgregación de la cultura española peninsular, América constituía su mejor salvaguardia. Por ello, en momentos muy oscuros de la historia patria, la catástrofe del exilio intelectual pudo revelarse a sus ojos como instrumento para estrechar vínculos que en modo alguno debían romperse, pero sobre todo para afianzar la conciencia de identidad hispánica abierta e integradora con que encarar un futu-

17 Escribe Luis Alberto Sánchez (1968, pp. 51-52): "Por su origen intelectual, por sus contactos universitarios y amistosos, por sus nuevas amistades americanas, es evidente que don Federico estaba con la República; sin embargo, y no porque alguien se lo impusiera, conservó un estricto equilibrio entre los antagonismos en juego desde 1931, y más propiamente desde el 18 de julio de 1936... Una vez, dolido de un comentario acerbo sobre su pretensa neutralidad ideológica, formulado por alguien del círculo de Neruda, me dijo don Federico: "iQué pena da no ser voluntariamente incomprendido y cómo duelen las inconsecuencias! Yo no soy un hombre de partido, pero tengo mis sentimientos y mis ideas y no las oculto ni traiciono»". 
ro menos azaroso. En fin de cuentas, si España era para Onís el fermento de toda creación original americana, paralelamente era América la razón última del ser histórico de España.

En los primeros años cuarenta Onís introduciría matices de una visión más equitativa en lo concerniente a las mutuas influencias. Así, en el ya citado trabajo "La eternidad de España en América", leído en diciembre de 1942 en New Orleans y publicado dos años más tarde, Onís reconocía que no sólo en ámbito literario, "sino en todos los aspectos de la cultura y de la vida, aun los más populares, hubo siempre en España un influjo considerable de América", y concluía afirmando la solidez perdurable de los vínculos constituidos por una tradición viva en estos términos:

Podemos suponer que llegue a desaparecer todo lo que desde España se estableció en América, como desapareció la estructura política de su organización colonial y tantas otras cosas del pasado -ni más ni menos que han desaparecido en España misma-; pero aquello que plantaron en América los españoles que tuvieron la voluntad de ser americanos -aquello que sin duda era lo más íntimo y popular de España, lo que tenía más fuerza de unidad, universalidad y libertad, lo que era más apto para transformarse y fundirse con los demás elementos que ofrecía la nueva realidadperdurará a través de todas las transformaciones que sufra este continente, cuyo destino, como ellos quisieron, es el de ir siempre en busca de un más allá ("La eternidad...", en Onís 1955, p. 19),

donde los conceptos de universalidad y libertad aplicados a España adquieren especial relieve si consideramos las difíciles circunstancias históricas de su país. Análogos matices a propósito de la pervivencia y la continuidad de la cultura hispánica comparecen en otro texto del mismo año, "España y el sudoeste de los Estados Unidos" ([1942], en Onís 1955, p. 25):

Esta América española y portuguesa es hoy por su extensión, por su vitalidad, por su capacidad asimilativa y creadora, por su promesa juvenil de crecimiento, el asiento principal de la cultura hispánica y por lo mismo debe ser el objeto primordial de nuestro interés, no sólo desde el punto de vista norteamericano por el hecho de ser nuestra vecina en la unidad natural e indestructible de este hemisferio, sino desde el punto de vista estrictamente hispánico, puesto que la cultura de España y Portugal, común a todos los pueblos hispánicos en lo que tiene de humano y per- 
manente, la encontraremos en América hoy más viva y universal que en Europa.

Observa a continuación Onís que entre las dos culturas europeas, anglosajona e ibérica, constitutivas de la americana, existe una importante analogía: si los Estados Unidos se organizaron como nación a partir de la idea de frontera, lo propio parece haber sucedido en la zona más septentrional del territorio hispánico en el continente, pues la misma energía conquistadora que la Castilla medieval concentrara en sus dinámicas fronteras peninsulares se transmite al dominio americano. "Cuando España llegó a fines del siglo Xvi a los límites posibles de su expansión y no hubo más allá a donde ir perdieron los españoles su manera natural y única de ser y de obrar y se inició la decadencia nacional" (p. 28). Alcanzado el punto de mayor dilatación del imperio, se inicia su contracción, su reflujo: un largo proceso dispersivo que Ortega había descrito, en una notable página de España invertebrada, situando su arranque a partir del año vigésimo del reinado de Felipe II; desde ese momento todo es desintegración inexorable en la imponente unidad territorial hispánica, con la pérdida de los Países Bajos y las subsiguientes del Milanesado, de Nápoles, de las grandes provincias de ultramar y de las colonias menores.

En 1900 -escribe Ortega (2005, p. 453)-, el cuerpo español ha vuelto a su nativa desnudez peninsular. ¿Termina con eso la desintegración? Será casualidad, pero el desprendimiento de las últimas posesiones ultramarinas parece la señal para el comienzo de la dispersión intrapeninsular. En 1900 se empieza a oír el rumor de regionalismos, nacionalismos, separatismos... Es el triste espectáculo de un larguísimo, multisecular otoño.

El hiato inútil y atroz de la Guerra Civil y la larga dictadura no pudo preverlo Ortega en 1922; el resto, sí. Onís conoce bien, y acaso tiene muy presentes, las poco halagüeñas conclusiones del análisis de su admirado amigo, pero escapa a ese fatalismo histórico con recurso al mismo concepto de frontera que le ha servido para definir lo esencial de la cultura hispánica:

La vitalidad española siguió y sigue todavía manifestándose en las fronteras y podemos estar seguros de que el destino de la cultura hispánica se está ahora decidiendo en México o Buenos Aires 
más que en España misma... El carácter español ha adquirido siempre su plena realización en la frontera. La lengua española se habla hoy de modo general con más cuidado y perfección en México o en Colombia. Las grandes obras de esa lengua se han escrito en las fronteras: el Cantar del Cid, en el siglo XII, en la frontera de Castilla con los moros; el Martín Fierro, en el siglo Xıx, en la frontera de la Pampa argentina con los indios. Este carácter español guerrero, conquistador, dinámico, y al mismo tiempo comprensivo, prudente y conciliador, que se formó en la frontera, es el que inspiró a los grandes clásicos españoles en sus creaciones universales, en las cuales siempre late un conflicto fronterizo ("España y el sudoeste...", en Onís 1955, p. 28) 18.

En esta circunstancia fronteriza -surgida en medio de hostilidades y antagonismos que en las páginas que comentamos se juzga oportuno soslayar-, ve Onís la más honda analogía entre los pueblos que se desarrollaron en la dinámica expansión de sus límites. Hay quizá en ello un eco de la sensata idea, propuesta por Herbert Bolton diez años antes -idea, por lo demás, poco atendida en la historiografía de entonces-, de aproximarse a la historia de América a partir del concepto de lo fronterizo como clave para una más amplia comprensión de los heterogéneos procesos coloniales en el continente. Onís lleva más lejos las cosas al sugerir que quienes dejaron sus tierras europeas para ganar las de América "eran mejores que los que se quedaron en ellas, eran representantes más típicos del carácter esencial de su raza" (p. 29), y que es en las virtudes encarnadas en los "mejores" de las culturas que se reparten el territorio americano (lo cual parece excluir a la población autóctona: "todos menos los indios vinieron de alguna parte"), en las que habrá de fundarse la unidad de América. "En momentos críticos como los presentes", concluye Onís, esa unidad "surge imponente, por encima de todas las diferencias, señalando a los pueblos todos americanos, ante el peligro común, la comunidad de su destino" (p. 31). Unidad que, de alcanzarse, daría respuesta a las alarmas que el drama de la disgregación cultural europea está suscitando en todo el continente, pues como observa por

${ }^{18}$ En un texto que, bajo el título "Unidad de España", se presenta como inédito en España en América (pp. 46-52), alude Onís a la importancia que para España tiene la idea de frontera, y cita el Facundo y el Martín Fierro como expresiones hispánicas de esa realidad fronteriza. El texto está fechado en 1918. 
entonces Alfonso Reyes (1997 [1941], p. 109), “América viene dando señales de inquietud ante la descomposición de Europa, que primero ensayó en España la virulencia de sus armas para luego entregarse abiertamente a su deporte hoy favorito: el destruir todo lo que construye" ${ }^{19}$. No es otra la inquietud de Onís a la vista del desastre europeo; si en sus elocuentes conclusiones está latente la esperanza, es porque un porvenir de incertidumbre las alienta.

¿Qué espacio reserva Onís a la componente amerindia en esta visión unitaria suya, tan afín al viejo ideal panamericano de fin de siglo? A juzgar por algún texto de estos años resulta difícil sustraerse a la impresión de un menosprecio; otros, en cambio, consienten cierta corrección de ese enfoque. Así, en "Cultismo y popularismo en México" (1944) o en "Lo mero espiritual" (1945), ambos publicados en los Estados Unidos, Onís pondera en la realidad mexicana una fusión de la cultura indígena y la española que, sin ser fenómeno generalizado en la América hispana -el caso del Perú vale para Onís como ejemplo de lo exacto opuesto-, basta para constatar la activa presencia de lo indígena como elemento constitutivo de una unidad nueva. México debe a esa amalgama su capacidad de transformar y enriquecer mediante producción original las tradiciones heredadas, y le debe también la facultad de perpetuar en su folklore las tendencias cultistas a las que se ha mostrado siempre proclive, la de refinar la lengua española llevándola a extremos de elegancia insospechados y, en definitiva, la de mantener saneada la herencia cultural hispánica, tal como puede verificarse en el plano literario apenas se confronta la vulgaridad decadente de la poesía tradicional española posterior al siglo XVI con la superior calidad de la que allí pervive. Pero, sobre todo, debe México a esta síntesis su carácter nacional, "ese algo inexplicable e indefinible que constituye el alma de un pueblo"; esa identidad depurada en el tiempo y fortalecida en las crisis, cuyas raíces se buscarán con provecho en la Conquista:

19 Algo después agrega Reyes (1997 [1941], p. 112): “Así pues, ante hechos como los que estamos presenciando, cuyo foco principal es Europa, cuyo foco secundario es Asia, y cuyo reflejo inmediato afecta al África, ¿pueden las medidas políticas unilaterales salvaguardar a América? ¿O en qué grado se la puede, al menos, inmunizar relativamente contra los inevitables trastornos generales, siquiera para evitar que se alcancen también entre nosotros los caracteres de catástrofe?”. 
Cada día se ve más claro por los historiadores que el carácter nacional del México moderno no empezó con la existencia de México como nación independiente, sino que existía ya durante la época colonial y se formó definitivamente a raíz de la conquista, como resultado de la fusión de la cultura española con la india. En esta primera y más honda crisis de México, el español creía que destruía o dominaba al indio, y éste luchaba activa o pasivamente, consciente o inconscientemente, para destruir o dominar al español, y, en realidad, lo que ocurrió es que el español se transformó en otro hombre al adaptarse al nuevo mundo mexicano y el indio se transformó en otro hombre al entrar en la nueva civilización traída por los españoles. El indio y el español fueron vencedores y vencidos en esta lucha; ambos tuvieron que morir para dar nacimiento a un nuevo hombre que ya no era español ni indio, sino mexicano ("Lo mero espiritual" [1945], en Onís 1955, pp. 138-139) ${ }^{20}$.

Reflexiones éstas que responden al más alto concepto de mestizaje cultural y dan fundamento a una crítica encomiástica de la obra de Onís. Verdad es que en esa obra conviven con otras interpretaciones de la realidad cultural americana de distinto cariz, pero lo es también que la inteligencia y la hábil retórica de nuestro autor aciertan siempre a armonizarlas o, digámoslo así, a alternarlas sabiamente.

La visión de una América proyectada hacia el futuro, antitética de la declinante cultura europea, se acentúa en los escri-

${ }^{20}$ En un posterior estudio dedicado al novelista colombiano Tomás Carrasquilla ("Tomás Carrasquilla, precursor de la novela americana moderna" [1951], luego publicado como prólogo de las Obras completas de este escritor que la editorial Epesa editó en Madrid en 1952), Onís (1955, pp. 643-644) observaba: "el gaucho o el llanero, el guajiro, el cholo o el indio, o cualquiera otro de los modos de ser rústico y popular en América, no pueden ser mirados como una curiosidad pintoresca y extraña por los autores americanos, si su arte no es falso, sino como la sustancia misma del carácter nacional en el que participan todos, cultos e incultos, y que sobrevive en las ciudades como en el campo de toda América, en un grado mayor o menor de fusión con los elementos modernos, internacionales y cosmopolitas que integran también, en mayor grado que en Europa, la cultura americana". Y en un texto de 1951, "Luis Palés Matos", Onís (1955, p. 672) pondera el alcance del mestizaje antillano, paradigma del de todo el continente: "La cultura de Cuba y Puerto Rico, como toda la de América, no consiste en una mezcla de elementos españoles con negros o indios, que se puedan de alguna manera aislar o separar; consiste en la creación como resultado de la mezcla de algo nuevo que ya no es ni negro ni indio ni español y es al mismo tiempo todas estas cosas". 
tos de Onís de estos años cuarenta. A fines de la década, en su conferencia bonaerense "La originalidad de la literatura hispanoamericana" alude a este contraste. Observa entonces que, a diferencia de América, Europa ha experimentado la rápida caducidad de sus modelos culturales en un sucederse de atropelladas y efímeras renovaciones, todas síntoma de su consunción:

A cada momento los europeos tenían la sensación de que la literatura estaba empezando en una nueva manifestación, con un nuevo nombre que surgía; que todo lo anterior había que echarlo por la borda para empezar de nuevo. La sensación de empezar de nuevo, de que se empezaba a vivir, era en realidad, la confirmación de que iban muriendo. Es un síntoma -ese aceleramiento de la vida- del acabamiento. En cambio, ese otro sentimiento americano del porvenir es la convicción de que nunca muere el pasado; de que el pasado, de una manera o de otra, queda siempre en todas las manifestaciones más modernas de la literatura; y se va, por lo tanto, formando como el sincretismo, la fusión o la integración de todas las formas pasadas que no necesitan morir para que vivan las presentes ("La originalidad...", en Onís 1955, p. 124).

Onís parece afrontar aquí la vieja convicción eurocéntrica de una cultura hispanoamericana subalterna siempre al impulso renovador europeo, el cual llegaría tardío o disminuido a las áreas alejadas del núcleo cultural que lo genera. En la rectificación propuesta, el nuevo continente no sólo custodia la integridad de la cultura de Occidente que el viejo dispersa y pierde, sino que es el único capaz de indicar el rumbo hacia el porvenir, pues la síntesis en que ha ido resolviendo sus antagonismos origina los más altos valores del tiempo presente: “iCuántos de estos mismos escritores americanos del siglo XIX que hemos citado, se nos han presentado con un valor cada vez más exaltado, según pasaba el tiempo! ¡Y cómo los han de ver, a medida que transcurren los siglos, enmarcados en la grandeza de América!" (p. 127). Y mientras esa obra se realiza para el reconocimiento venidero, de uno a otro extremo del continente busca el hombre americano -el de los Estados Unidos como el de Brasil y el de toda Hispanoamérica- respuesta a la pregunta esencial sobre su identidad. "Y de sus trabajos surge, afirmándose cada vez más, la convicción de que América no es Europa, aunque se sienta heredera y continuadora de ella. Y de esa manera, América se salvará a sí misma y salvará a Europa” (p. 128). 
Sólo seis años antes de hacer Onís estas esperanzadas consideraciones, se había preguntado Alfonso Reyes con sensata cautela qué sentido podía tener, a la vista del desastre europeo, una discusión americana sobre el papel del nuevo continente en la elaboración de una síntesis cultural alternativa, y no había dejado de observar que podría tratarse a lo sumo "de recoger la herencia de una cultura, ante el notorio quebranto de los pueblos que la han construido" ${ }^{21}$. El hecho de que en 1949 Onís hablara ya de un relevo enteramente realizado en ese sentido y se mostrara persuadido de que era América el porvenir de Europa, en medio de circunstancias históricas radicalmente distintas y ante un nuevo panorama internacional que las tensiones entre las dos grandes superpotencias hacían sumamente inestable, es desde luego revelador de su confianza en el potencial cultural americano.

La ruptura dolorosa de Onís con la España oficial a que la Guerra Civil lo había abocado ${ }^{22}$ y su alarma ante la crisis de la cultura europea nos permiten entender también ciertas actitudes personales de cuya intensidad nos ha llegado noticia en testimonios de amigos, colegas y alumnos. A través de ellos se nos manifiesta el fuerte temperamento de un hombre dispuesto en todo momento a defender sus convicciones en la pétrea solidez de la argumentación más que en la actitud dialogante, pero capaz también de seducir con la hondura de sus percepciones, con su impar brillantez didáctica y hasta con extremos de generosidad y afecto imprevistos en carácter tan adusto. Se intuye en Onís ese modo muy castellano de ocultar la sensibilidad en la aspereza, igual que en sus páginas sobre América y España se adivinan inquietudes bajo la robustez del discurso. Pero la contención de una tensión íntima que Onís observó en la escritura, en la actitud vital no pudo pasar inadvertida:

21 "Posición de América”, conferencia leída en el III Congreso del Instituto Internacional de Literatura Iberoamericana, celebrado en New Orleans en diciembre de 1942 y recogida en Reyes 1997, pp. 254-270.

${ }^{22}$ En la necrológica publicada en El Nacional de Caracas el domingo 23 de octubre de 1966, decía Arturo Uslar Pietri (1967, p. 206): "No estuvo nunca enteramente de acuerdo con la vana parlería de muchos de sus amigos republicanos, pero cuando la República fue destruida a sangre y fuego, se quedó con su derrotada bandera, en un destierro a que él mismo se había condenado. Sólo los que lo conocimos cercanamente podemos medir la inmensidad del sacrificio que fue para él renunciar voluntariamente de por vida a volver a España”. 
Su hispanidad -escribía, con motivo de un homenaje, Victoria Ocampo (1968, p. 28)- era patente e inconscientemente agresiva. Cuando yo lo veía en su casa de campo, escarbando la tierra de Massachusetts (creo que era este Estado) en beneficio de sus plantas -ocupación que le deleitaba- me repetía a mí misma: "iQué ha de ser éste suelo americano! En cuanto estas manos lo remueven, es suelo español. Estas manos pueden más que la tierra extranjera. ¿Qué tozudez tiene metida en la sangre este hombre!"23.

Y Andrés Iduarte (1968, p. 21), que habló de Onís con reconocimiento y afecto, recordaba que "dentro de una exterior tiranía intelectual, soltaba por momentos al estudiante talentoso y rebelde, y admitía y transigía, con absoluto respeto para los diferentes criterios filosóficos o políticos, pero para volver en seguida a sus normadoras exigencias". Por no hablar de los agrios silencios o las extemporáneas reacciones de Onís en sus reuniones semanales ante el contertulio incauto y mal documentado. Como si un desasosiego interior, brillantemente resuelto en el juego de equilibrios de su escritura, no pudiera dejar de aflorar en sus relaciones humanas más inmediatas.

En los primeros años cincuenta, conjurado el desastre europeo, los matices salvíficos precedentes se atenúan en la reflexión crítica de Onís, sin que pierda fuerza de convicción su alegato en pro de "la España que vive de otra forma en América" ("Andrés Iduarte" [1951], en Onís 1955, p. 676). Este concepto sigue siendo cardinal en las páginas que dedica a escritores como José Martí -visto ahora como no encasillable precursor de una modernidad hispanoamericana reacia, a su vez, a las fáciles clasificaciones ${ }^{24}-$, o a figuras contemporáneas como Alfon-

23 También Germán Arciniegas (1968, p. 44) se refiere a esa "hispanidad" a ultranza de Onís: "América -la nuestra- lo había embrujado, y cuando llegó la hora de salir de Nueva York, se fue a San Juan de Puerto Rico. Como Juan Ramón, como Salinas... Volver a cruzar el Atlántico, eso no. Pero aclaremos: no viajaba; seguía en Castilla. Encastillado".

24 "Martí fue precursor no sólo del movimiento modernista en que Rubén Darío pensaba y por hábito todos solemos pensar, que es el que deriva de sus Prosas profanas, sino de una modernidad más amplia, que abarca no una sino la totalidad de las tendencias de la época. Si miramos el modernismo como debe mirarse, no como una escuela literaria, sino como una época, que fue el principio de esta en que vivimos todavía, Martí se nos impone como el creador y sembrador máximo de las ideas, formas, y tendencias que han tenido la virtud de perdurar en ella como dominantes, y que están 
so Reyes, Tomás Carrasquilla, Luis Palés Matos, Andrés Iduarte o los poetas modernistas de su Anthologie de la poésie ibéro-américaine. Onís dirige otra vez la mirada a la crisis finisecular, que en ámbito cultural hispánico se manifestó en la varia modulación del Modernismo, para determinar con mayor precisión los orígenes de una percepción de la realidad española y americana destinada a ofrecernos más honda visión de nuestro pasado y nuestro porvenir:

La concepción de América de Martí, como la ruta de su vida, se mueve en el triángulo Hispanoamérica-España-Estados Unidos, la misma ruta y concepción que seguirá Rubén Darío poco después y más o menos fielmente la mayor parte de los modernistas. La significación de la fecha de 1898, en la que hizo crisis histórica ese triángulo, y que ha sido escogida como denominación de la generación modernista española en contraposición a la americana, fue prevista por Martí desde 1889 hasta su muerte en 1895 y es en América donde alcanzó mayor repercusión y más hondo sentido. Es entonces cuando los americanos piensan a América en función de España, como algo propio, y los Estados Unidos, como algo ajeno, y adquieren nueva conciencia de su pasado y su porvenir, mientras algunos españoles empiezan a descubrir a España en América (“Martí...”, en Onís 1955, p. 626).

Americanos como Darío, Güiraldes, Neruda y en general "todo escritor de verdadera valía" procederán a recomponer la unidad de visión del precursor Martí, rota en la lucha entre europeístas y criollistas durante el período álgido del Modernis$\mathrm{mo}^{25}$. La fecha clave del fin de siglo le permite a Onís resaltar confluencias: mientras América se interrogaba sobre su identidad, los españoles del 98 han buscado ante esa misma crisis las respuestas para el problema de España, y estos paralelos desarrollos han permitido superar diferencias y han propiciado el

cada vez más llenas de posibilidades para el futuro" "José Martí: valoración" [1952], en ONís 1955, p. 619).

${ }_{25}$ Onís prefiere subrayar lo que en el Modernismo hay de quiebra, más que de proceso ya muy avanzado de afirmación americana. En el plano literario, Henríquez Ureña (2014 [1949], p. 285) había situado esta afirmación de independencia en las primeras décadas del siglo xıx: "la busca de una expresión artística que nos fuera propia, y no subsidiaria de Europa, había comenzado, según hemos visto, ya en 1823, cuando Bello proclamó nuestra independencia literaria en la primera de sus Silvas americanas; renováronla en 1832 Echeverría y los románticos; reapareció con Martí y Rodó, y aun con Darío". 
acercamiento fecundo, la conciencia de un porvenir común, de un mismo destino. Esta aproximación ha hecho a su vez posible que el reconocimiento de la originalidad hispanoamericana haya encontrado expresión en España, en las autorizadas voces de Unamuno y Menéndez Pelayo, antes incluso que en la propia América. El Modernismo, nacido en los rescoldos de una larga tradición romántica, ha sido el lugar de encuentro. El Modernismo ha marcado el fin de una época y el principio de otra; ha reaccionado contra lo pretérito y ha absorbido las nuevas influencias -y no sólo la francesa, de cuya prevalencia más bien se libera al abrirse a las de otras literaturas-; ha generado fuertes individualidades y ha dado cabida a las más altas manifestaciones de una originalidad creadora americana que por vez primera ejerce su ascendiente en la literatura española. En una América que "es por naturaleza nueva, libre, individualista, imaginativa y poética, original y cosmopolita, antigua y moderna, mezcla de razas y culturas" ("Martí...", en Onís 1955, p. 626), el Modernismo ha significado la definitiva independencia de la evolución literaria europea. Mientras que las literaturas de Europa procedían a la liquidación del propio pasado para abrirse a nuevas e infecundas experimentaciones, al punto que Onís se siente autorizado a hablar de decadencia, Hispanoamérica se ha mantenido receptiva a todas las tradiciones y estrechamente vinculada a la propia, y ello "no por falta de modernidad, sino porque el americano de todos los tiempos, llámese sor Juana, Rubén Darío o Neruda, no puede renunciar a ningún pasado, sino que necesita integrarlo en el presente" ("La poesía iberoamericana" [1954], en Onís 1955, p. 166) ${ }^{26}$. Es ese vínculo el que ha consentido el reconocimiento entre americanos y españoles; es también el que permite concebir a América como salvaguardia de la cultura hispánica. A él queda circunscrita toda originalidad e independencia intelectual de Hispanoamérica.

${ }^{26}$ Encontramos esta misma idea en "La originalidad..." (ONís 1955, p. 124): "En cambio, ese otro sentimiento americano del porvenir es la convicción de que nunca muere el pasado; de que el pasado, de una manera o de otra, queda siempre en todas las manifestaciones más modernas de la literatura; y se va, por lo tanto, formando como el sincretismo, la fusión o la integración de todas las formas pasadas que no necesitan morir para que vivan las presentes. Esto se podría ver en todo escritor hispanoamericano que tenga valor". 
Cuando en 1955 redacta Onís el prefacio de España en América, alude en síntesis a las circunstancias que han determinado las dos etapas en que divide su vida: de las que lo han mantenido durante la mayor parte de ella físicamente alejado de España derivan casi todos los trabajos reunidos en el libro: "Es inevitable -reconoce- que haya en ellos algunas contradicciones y muchas más repeticiones. Las contradicciones las he dejado para que se vea la evolución de mi pensamiento a través de los cambios de la época en que me ha tocado vivir y de los diferentes ambientes en que he tenido que moverme" (p. 10). Tales discordancias no son sustanciales: los acontecimientos del más conflictivo siglo que la historia ha conocido no alteraron en lo esencial su interpretación del sentido de la cultura hispánica. Las más significativas revisiones de sus ideas se concentran en las páginas que dedicó a los dos momentos históricos que en mayor medida le interesaron: el Renacimiento español y el Modernismo hispanoamericano, terreno, el primero, de debate sobre la génesis de nuestra modernidad, y el segundo culminación de una entera época histórica cuyos síntomas de disolución eran ya anuncio y germen de la nueva. En ambos trances, la cultura hispánica había sido capaz de persistir conjurando el riesgo de disgregación y trascendiendo los propios límites geográficos, lo cual le otorgaba un grado de unidad acaso no alcanzado por ninguna otra en la moderna historia de Occidente. Por creerlo así, Onís preservó siempre la visión idealizada de los valores patrios que en su juventud se había forjado bajo influencia de los mejores maestros y que fue punto de referencia constante en su obra crítica. El mérito de su contribución al conocimiento de nuestras letras a la vista está y no hace falta encarecerlo aquí; su pertinaz aferrarse a un "acendrado e insobornable españolismo" (como en cierta ocasión dijo él refiriéndose a Lorca) acaso resulte hoy un tanto herrumbroso y anacrónico, pero en tiempos como los nuestros, en que la influencia española en la mucho más vasta realidad de la cultura hispanoamericana parece avanzar con paso firme hacia la irrelevancia, tal vez sea oportuno tener presentes las reflexiones de Onís acerca de su capacidad de pervivencia. Y convendrá no olvidar el alto valor de su empeño por mantener tendidos todos los puentes culturales entre América y España. 


\section{REFERENCIAS}

Albert Robatto, Matilde 1997. "La querencia americana de Federico de Onís", en El reino de la memoria, Universidad de Puerto Rico, Río Piedras, pp. 86-117.

Albert Robatto, Matilde 2002. "Federico de Onís entre España y Estados Unidos", en Los lazos de la cultura. El Centro de Estudios Históricos de Madrid y la Universidad de Puerto Rico. Eds. Consuelo Naranjo Orovio y Miguel Ángel Samper, Consejo Superior de Investigaciones Científicas, Madrid, pp. 237-266.

Albert Robatto, Matilde 2003. Federico de Onís: cartas con el exilio, Eds. do Castro, A Coruña.

Anderson Imbert, EnriQue 2014 [1954]. Historia de la literatura hispanoamericana. T. 1: La colonia. Cien años de República, Fondo de Cultura Económica, México.

Arciniegas, Germán 1968. "Don Federico o el conquistador conquistado", La Torre, 16, 59, pp. 37-44.

Arrigoitia, Luis M. DE 1968. "Bibliografía de Federico de Onís", La Torre, 16,59 , pp. 229-262.

Arrigoitia, Luis M. DE 1985. "Federico de Onís y Gabriela Mistral. Relación literaria y amistad de por vida”, Revista de Estudios Hispánicos, 12, pp. 31-52.

Babín, María Teresa 1968. "Don Federico de Onís en mi recuerdo", Revista Hispánica Moderna, 34, 1/2, pp. 11-12.

Bolton, Herbert H. 1933. "The Epic Greater America”, The American Historical Review, 38, 3, pp. 448-474, doi: 10.2307/1837492.

Cardona, Rodolfo 2007. "Correspondencia entre el profesor don Federico de Onís-Harriet de Onís y don Ramón del Valle-Inclán-Josefina Blanco", Anales de la Literatura Española Contemporánea, 32, 3, pp. 703-742.

Carpentier, Alejo 1990. Obras completas. T. 13: Ensayos, Siglo Veintiuno Editores, México.

Castagnino, Raúl H. 1968. "Lo americano y lo argentino en el pensamiento de Federico de Onís", Revista Hispánica Moderna, 34, 1/2, pp. 13-19.

Elliott, John H. 1970. El Viejo Mundo y el Nuevo (1492-1650), Alianza Editorial, Madrid.

Fernández Granell, Eugenio 1968. "Recuerdo parcial de don Federico de Onís”, La Torre, 16, 59, pp. 55-80.

Florit, Ricardo 1968. "Federico de Onís: bibliografía", Revista Hispánica Moderna, 34, 1/2, pp. 95-100.

García Morales, Alfonso 1998. "Federico de Onís y el concepto de modernismo. Una revisión”, Revista Iberoamericana, 64, 184/185, pp. 485-506, doi: $10.5195 /$ reviberoamer.1998.6123.

Henríquez Ureña, Pedro 2014 [1949]. Las corrientes literarias en la América hispánica, Fondo de Cultura Económica, México.

IDUARTE, ANDrés 1968. "Don Federico de Onís en vida y muerte", Revista Hispánica Moderna, 34, 1/2, pp. 20-24.

Laguerre, EnriQue A. 1968. "La España de don Federico de Onís", Revista Hispánica Moderna, 34, 1/2, pp. 25-30. 
Lezama Lima, José 1993. La expresión americana, Fondo de Cultura Económica, México.

Martí, José 2004. Ensayos y crónicas. Ed. José Olivio Jiménez, Cátedra, Madrid.

Meléndez, Concha 1968. "Federico de Onís y la América hispana”, Revista Hispánica Moderna, 34, 1/2, pp. 31-36.

Navarro, Joaquina 1968, "La obra hispanista de Federico de Onís", Revista Hispánica Moderna, 34, 1/2, pp. 37-46.

OcAmpo, Victoria 1968. "Recordando a don Federico", La Torre. Revista General de la Universidad de Puerto Rico, 16, 59, pp. 25-28.

Onís, Carlos DE 1985. "El magisterio de Unamuno en el hispanista Federico de Onís", Confluencia, 1, 1, pp. 1-29.

ONís, Federico De 1952. "Valoración", Revista Hispánica Moderna, 18, 1/4, pp. 145-150.

Onís, Federico DE, 1955. España en América. Estudios, ensayos y discursos sobre temas españoles e hispanoamericanos, Eds. de la Universidad de Puerto Rico, Madrid-Caracas.

Ortega y Gasset, José 2005 [1922]. España invertebrada, en Obras completas, t. 3, Santillana-Ediciones Generales-Fundación José Ortega y Gasset, Madrid.

Picón-Salas, Mariano 1944. De la Conquista a la Independencia. Tres siglos de historia cultural latinoamericana, Fondo de Cultura Económica, México.

Picón-Salas, Mariano 1953. Obras selectas, Eds. Edime, Madrid-Caracas.

Reyes, Alfonso 1946. Letras de la Nueva España, Fondo de Cultura Económica, México.

Reyes, Alfonso 1997. Obras completas, t. 11, Fondo de Cultura Económica, México.

Rivera de García, Eloísa 1968. "Don Federico de Onís, gestor de la cultura puertorriqueña”, Revista Hispánica Moderna, 34, 1/2, pp. 62-70.

Rodríguez-Alcalá, Hugo 1968. "Sobre el americanismo de Federico de Onís”, Revista Hispánica Moderna, 34, 1/2, pp. 71-84.

Roggiano, Alfredo A. 1967. "Federico de Onís (1885-1966)", Revista Iberoamericana, 33, 63, pp. 119-121.

Ruiz Manjón, Octavio 2012. "Federico de Onís: figura clave en la historia de las relaciones culturales entre España y los Estados Unidos", Memoria y Civilización, 15, pp. 397-413.

SÁnchez, Luis Alberto 1968. "Don Federico (recuerdo)", Revista Hispánica Moderna, 34, 1/2, pp. 85-87.

Torre, Emilio De 1968. "Mis años con don Federico", Revista Hispánica Moderna, 34, 1/2, pp. 88-92.

Torrente Ballester, GonZalo 1984. El Quijote como juego y otros trabajos críticos, Destino, Barcelona.

Unamuno, Miguel de 1968. Obras completas. T. 3: Nuevos ensayos, Escelicer, Madrid.

Uslar Pietri, Arturo 1967. "Federico de Onís (1885-1966)”, Hispanic Review, 35, 2, pp. 205-207.

Young, Howard 1997. "Federico de Onís (1888-1966)", Hispania, 80, 2, pp. 268-270, doi: 10.2307/345886. 